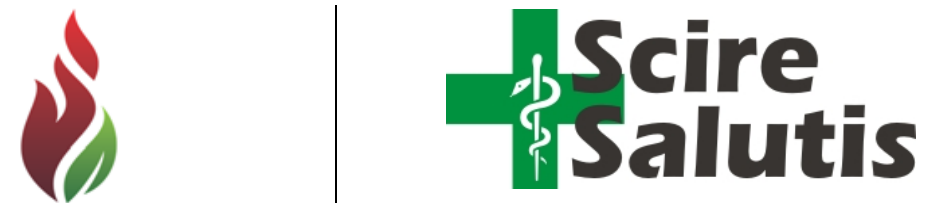

SUSTENERE

Publishing Corporation

Journals Homepage:

www.sustenere.co/journals

Scire Salutis, Aquidabã, v.4, n.2, Abr, Mai, Jun, Jul, Ago, Set 2014.

ISSN 2236-9600

\section{QUALIDADE DE VIDA E ÁGUA PARA CONSUMO HUMANO NOS MUNICÍPIOS DE MALHADA DOS BOIS E SANTO AMARO DAS BROTAS}

\section{RESUMO}

Água é vital e constitui elemento essencial à vida vegetal e animal, porém quando contaminada, é considerada uma das principais causas de doenças causando prejuízo para a humanidade. O presente estudo teve como objetivo analisar a qualidade da água para consumo humano no município de Malhada dos Bois e Santo Amaro das Brotas e sua influência na qualidade de vida da população. Os dados foram obtidos através do Relatório de Controle de Qualidade do ano de 2014 da Companhia de Saneamento Básico do Estado de Sergipe e no site do DATASUS. Os resultados indicam que o município de Santo Amaro da Brotas está em desacordo com a Portaria 2.914/2011 do Ministério da Saúde que dispõe sobre os procedimentos de controle e de vigilância da qualidade da água para consumo humano e seu padrão de potabilidade. A qualidade da água utilizada no município de Malhada dos Bois está dentro dos parâmetros estabelecidos. Os dados epidemiológico, revelam que o município de Santo Amaro da Brotas apresentou um quadro de morbidade com internação por doenças infecciosas e parasitárias maior que o município de Malhada dos Bois Há uma discrepância sobre mortalidade causada pelas doenças infecciosas e parasitárias entre os municípios, apenas um registro em 2011 em Malhada dos Bois e em Santo Amaro das Brotas apresentou dois óbitos em 2010, três óbitos em 2011 e quatro óbitos em 2012. Os organismos humanos são infectados pelos micro-organismos por via cutânea ou por ingestão de água contaminada; pelo contato primário com águas de recreação e ainda por ingestão de líquidos ou de alimentos contaminados, durante o preparo de alimentos ou em seu ambiente de origem influenciando diretamente na sua qualidade de vida.

PALAVRAS-CHAVES: Qualidade de Vida; Água Potável; Doenças Parasitárias Intestinais.

\section{QUALITY OF LIFE AND WATER INTENDED FOR HUMAN CONSUMPTION IN THE MUNICIPALITIES OF MALHADA DOS BOIS AND SANTO AMARO DAS BROTAS}

\section{ABSTRACT}

Water is vital and is an essential element for plant and animal life, but when contaminated, is considered a major cause of diseases to humans, causing damage to humanity. The present study aimed to analyze the quality of water for human consumption in the city of the Malhada dos Bois-SE, Brazil and Santo Amaro das Brotas-SE, Brazil and its influence on quality of life. Data were obtained from the Quality Control Report of 2014 of the Basic Sanitation Company of the State of Sergipe, Brazil and DATASUS site. The results indicated that the municipality of Santo Amaro das Brotas is at odds with the Ordinance 2914/2011 of the Ministry of Health, which sets forth the procedures for the control and surveillance of water quality for human consumption and its potability standards. The same problem is not found in the quality of water used in the Malhada dos Bois-SE, Brazil city are within the established parameters. Regarding the epidemiological data, it was observed that the municipality of Santo Amaro da Brotas-SE, Brazil presented a framework of greater morbidity and hospitalization for infectious and parasitic diseases that the Malhada dos Bois-SE, Brazil city when analyzing the years 2010 to 2013 is observed also that there is discrepancy in mortality from infectious and parasitic diseases among municipalities. In the years 2010, 2011 and 2012 there was only one death record in Malhada dos Bois-SE, Brazil in 2011 while Santo Amaro das Brotas-SE, Brazil had two deaths in 2010, three deaths in 2011 and four in 2012 all deaths from infectious and parasitic diseases. Human organisms are infected by micro-organisms through the skin or by ingestion of contaminated water; the primary water contact recreation and even swallowed liquid or contaminated during food preparation or in their environment of origin directly influencing the quality of life.

KEYWORDS: Quality of Life; Drinking Water; Intestinal Parasitic Diseases.

\section{SECTION: Articles}

TOPIC: Qualidade de Vida

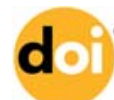

DOI: 10.6008/SPC2236-9600.2014.002.0001

\author{
Maria Cecília Mendonça \\ de Araújo Alves \\ Universidade Tiradentes, Brasil \\ http://lattes.cnpq.br/7846706944070897 \\ mar cecili@yahoo.com.br
}

Received: 05/02/2014

Approved: 15/09/2014

Reviewed anonymously in the process of blind peer.

Referencing this:

ALVES, M. C. M. A.. Qualidade de vida e água para consumo humano nos municípios de Malhada dos Bois e Santo Amaro das Brotas. Scire Salutis, Aquidabã, v.4, n.2, p.6-13, 2014. DOI:

http://dx.doi.org/10.6008/SPC2236$\underline{9600.2014 .002 .0001}$ 


\section{INTRODUÇÃO}

O estímulo ao consumo exagerado, o excesso de utilização de produtos químicos na pecuária, o incentivo à agricultura com a utilização de diversos defensivos agrícolas para combater pragas e o aumento das áreas irrigadas, são exemplos de temas atuais amplamente discutidos devido aos impactos causados ao meio ambiente como: contaminação de mananciais, diminuição dos leitos dos rios e acesso a água de má qualidade que reflete na saúde e consequentemente na qualidade de vida da população, principalmente as de maior vulnerabilidade social.

Além disso, outro agravo decorrente da devastação do meio ambiente são as mudanças climáticas e os desastres naturais que aumentam os riscos de adoecimento das populações (ONU, 2012).

O uso mundial de água é estimado em cerca de quatro mil quilômetros cúbicos por ano, porém, um bilhão de pessoas não têm acesso à água potável de acordo com a UNESCO. Esse fato está diretamente relacionado aos agravos das epidemias que acometem as populações humanas. Desta forma, o acesso a água de boa qualidade vem sendo foco de discussões. No Brasil, esse assunto tem ocupado a agenda de gestores e ganhado adeptos com base no princípio de que todas as pessoas têm direito de estar protegidas de poluição, viver e desfrutar de um ambiente limpo e saudável (HABERMANN \& GOUVEIA, 2008).

Os agravos decorrentes da ação antrópica afetam a sua qualidade de vida e tornam-se um desafio. Sabe-se que fatores econômicos podem influenciar as condições de saúde, as atividades sociais e a avaliação subjetiva da saúde, tanto na percepção das capacidades funcionais quanto na qualidade de vida (ROSA et al., 2007). A noção de qualidade de vida transita, em um campo semântico polissêmico, onde de um lado está relacionado ao modo de vida, suas condições e estilos. De outro, inclui ideias sobre o desenvolvimento sustentável e sobre os direitos humanos e sociais. Estas noções unem-se em uma resultante social de construção coletiva dos padrões de conforto e segurança que determinada sociedade estabelece como referência (PIMENTA et al., 2008).

Publicações da OMS foram pioneiras na utilização de uma clara definição do conceito de qualidade de vida para orientar as pesquisas (FLECK et al., 1999). Uma equipe da OMS denominada Grupo de Qualidade de Vida da Organização Mundial de Saúde (OMS) - Whoqol Health Organization Quality of Life Group (WHOQOL) - definiu qualidade de vida como "a percepção dos indivíduos de sua posição na vida, no contexto dos sistemas culturais e valores nos quais ele vive e em relação aos seus objetivos, expectativas, padrões e preocupações" (OMS, 2005; BONOMI et al., 2000). A dificuldade de definir e conceituar QV continua como um constante desafio (BERTOLETTI et al., 2014).

A satisfação das necessidades do ser humano está relacionada a sua qualidade de vida. A globalização leva a mudanças sociais e econômicas e, como consequência, as pessoas procuram um maior consumo em busca de bem-estar. Deve-se, portanto, haver uma tentativa de equilíbrio 
entre o estilo de vida e a classe social, além de uma sustentabilidade no consumo tanto de bens duráveis, não duráveis e dos recursos oferecidos pela natureza por conscientização e mudança de hábitos (FRANCISCHETTI et al., 2014).

A saúde e a qualidade de vida dos brasileiros têm melhorado nas últimas décadas (VASCONCELOS et al., 2001), em decorrência da sua valorização na pauta de saúde do país, com ações voltadas à saúde, especialmente dos setores privado e público (BUSS, 2000).

A $Q$ V, pode ser medida por diferentes instrumentos validados e avaliada em todas as nações, considerando-se as idades e gêneros, principalmente como avaliação de pacientes portadores das mais diversas afecções de saúde física e mental (PRIEBE et al., 2008).

A qualidade da água é definida por sua composição química, física e bacteriológica. Para o consumo humano, há necessidade de água cristalina e saudável, livre de cor, gosto, odor e qualquer substância que possa produzir efeito fisiológico prejudicial à saúde do homem, o que é denominado de água potável. (SANTOS, 2014).

Dados da UNICEF revelam que no mundo aproximadamente 1.800 mil crianças com menos de cinco anos morrem diariamente de doenças, ligadas à água, ao saneamento e a higiene. Os grupos patogênicos mais comumente associados a doenças de veiculação hídrica estão relacionados no Quadro 1.

Quadro 1: Organismos patogênicos de veiculação hídrica.

\begin{tabular}{|c|c|}
\hline Categoria & Patogênicos de Veiculação Hídrica \\
\hline Bactérias & Víbrio cholerae, Salmonella, Shigella, Legionella, Campilobacter Yersinia, S. typhi, Coliformes \\
totais e fecais
\end{tabular}

Fonte: Chapra (1997); Boland (1993).

Serviços de saneamento desempenham um importante papel no controle da transmissão de inúmeras agentes patogênicos, principalmente os vírus que causam gastroenterite aguda e hepatite. Os agentes virais com maior impacto na saúde pública são vírus da hepatite $A$, rotavírus e norovírus, adenovírus, enterovírus contaminam muitos ecossistemas aquáticos brasileiros. A circulação de vírus no meio ambiente tem sido relacionada a condições sanitárias locais inadequadas, incluindo as baixas coberturas de serviços e ineficazes tecnologias convencionais utilizadas para eliminar ou reduzir a carga viral em água ou esgoto (PRADO \& MIAGOSTOVICH, 2014).

A análise físico-química e microbiológica da água constitui importantes ferramentas para a determinação da qualidade da água de consumo humano. Como a qualidade da água é um fator imprescindível à manutenção da saúde humana, este estudo tem como objetivo analisar dados documentais e registros referentes a análise da qualidade da água e saúde dos municípios de Malhada dos Bois e Santo Amaro das Brotas em Sergipe. 


\section{METODOLOGIA}

A pesquisa tem caráter qualitativo. Utilizou-se como metodologia a pesquisa documental através de relatório da Companhia de Saneamento do Estado de Sergipe - DESO e da Secretaria de Estado de Saúde e sites de instituições como: IBGE e DATASUS.

O Estado de Sergipe está situado na Região Nordeste e tem por limites o oceano Atlântico a leste, os Estado da Bahia, a oeste e a sul, e o Estado de Alagoas, a norte, do qual está separado pelo Rio São Francisco. Com 75 municípios, é o menor dos estados brasileiros, ocupando uma área total de 21.915,116 km². Em 2010, sua população foi recenseada em 2.068.017 habitantes (IBGE, 2010).

Em Sergipe o tratamento da água é realizado pela Companhia de Saneamento de Sergipe (DESO), que é responsável pela produção de água potável a partir de 122 unidades de tratamento. Para que isso ocorra, utiliza tecnologia apropriada, adequada à qualidade e característica da água bruta de cada manancial. Para atingir os níveis recomendados de potabilidade é realizado o controle de dosagem de produtos químicos e acompanhamento dos padrões de qualidade. Nesse processo, o tratamento da água bruta passa por etapas como: cloração, coagulação, floculação, desinfecção e fluoretação, contribuindo, dessa forma, para a melhoria dos indicadores de saúde pública. $O$ tratamento da água é diretamente responsável pela redução das doenças de veiculação hídrica e pela queda no índice de mortalidade infantil.

Segundo a DESO, a água fornecida à população sergipana segue as exigências do Ministério da Saúde. Essa determinação se torna uma garantia com o trabalho de monitoramento do produto. A água passa por análises em laboratório próprio da empresa e em unidades laboratoriais terceirizadas com certificações ISO/IEC 17025. E, mensalmente, são emitidos relatórios de controle de qualidade para as Coordenadorias de Vigilância Sanitária. Toda água captada e tratada é monitorada desde o manancial até o ramal do imóvel do cliente. A cada mês, a empresa chega a coletar 3.535 amostras e efetiva 28.050 ensaios analíticos em todo o território sergipano atendido.

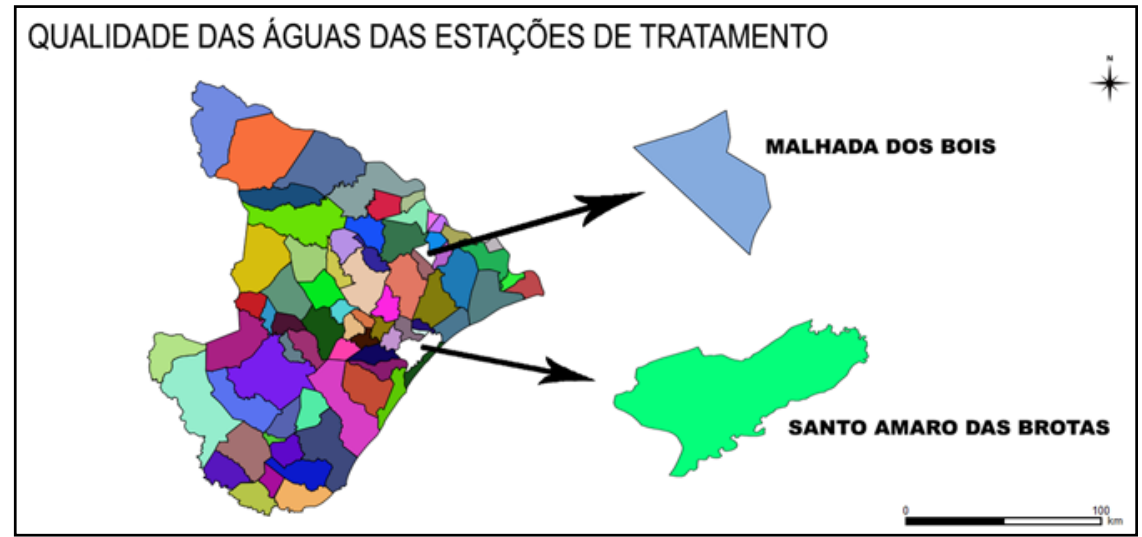

Figura 1: Qualidade das águas das estações de tratamento 
O presente estudo compreende municípios de Malhada dos Bois e Santo Amaro das Brotas do Estado de Sergipe, inseridos, nas Bacias Hidrográficas do Rio São Francisco, Rio Japaratuba e Rio Sergipe (Figura 1).

A escolha dos municípios deve-se ao fato do Relatório do Controle de Qualidade 2014 da DESO apontar diferenças nos resultados das análises das águas para o consumo humano nas Estações de Tratamento da Água (ETA) desses municípios.

\section{RESULTADOS E DISCUSSÕES}

Foram analisados os dados descritos no relatório do controle de qualidade de 2014 da DESO em relação a analises da água nas ETA e do DATASUS sobre as doenças de veiculação hídricas no Estado de Sergipe.

Os dados escolhidos estão contidos no relatório da DESO e referem-se as análises das águas das ETA dos dois municípios, de acordo com parâmetros estabelecidos pelo Conselho Nacional de Meio Ambiente (CONAMA/518/2004) e com os valores máximos permitidos (VMP) publicados na Portaria 2.914/2011 do Ministério da Saúde (MS). Os limites de qualificação (LQ) também foram realizadas pelo Laboratório de Estudos Ambientais do Instituto de Tecnologia e Pesquisa para a DESO e encontram-se registrados no mesmo documento.

No quadro 2 estão relacionados os parâmetros físico-químicos e microbiológicos utilizados pelo Laboratório de Estudos Ambientas - LEA do Instituto de Tecnologia e Pesquisa- ITP na análise das águas dos rios que servem para abastecer os municípios estudados.

\begin{tabular}{|c|c|c|c|c|}
\hline \multirow[b]{2}{*}{ Substâncias } & \multicolumn{2}{|c|}{ Resultado } & \multirow[b]{2}{*}{ Unidade } & \multirow[b]{2}{*}{ VMP } \\
\hline & $\begin{array}{c}\text { ETA Visgueiro } \\
\text { Malhada dos Bois } \\
\text { Coleta } \\
17.02 .2014\end{array}$ & $\begin{array}{c}\text { ETA } \\
\text { Santo Amaro } \\
\text { Coleta 28.04.2014 }\end{array}$ & & \\
\hline Alumínio & $<0,1$ & $<0,1$ & $\mathrm{mg} / \mathrm{L}$ & 0,2 \\
\hline Nitrogênio - Aminiacal (Amonia) & $<0,10$ & $<0,10$ & $\mathrm{mg} / \mathrm{L}$ & 1,5 \\
\hline Cloreto & $<3,0$ & 37,5 & $\mathrm{mg} / \mathrm{L}$ & 250 \\
\hline Cor Aparente & $<5,0$ & 53,6 & $\mathrm{uH}$ & 15 \\
\hline Diclorobenzeno 1,2 & $<0,001$ & $<0,001$ & $\mathrm{mg} / \mathrm{L}$ & 0,01 \\
\hline Diclorobenzeno 1,4 & $<0,001$ & $<0,001$ & $\mathrm{mg} / \mathrm{L}$ & 0,03 \\
\hline Dureza Total & 26,1 & 306 & $\mathrm{mg} / \mathrm{L}$ & 500 \\
\hline Etilbenzeno & $<0,001$ & $<0,001$ & $\mathrm{mg} / \mathrm{L}$ & 0,2 \\
\hline Ferro Total & $<0,05$ & 0,70 & $\mathrm{mg} / \mathrm{L}$ & 0,3 \\
\hline Manganês Total & $<0,07$ & $<0,07$ & $\mathrm{mg} / \mathrm{L}$ & 0,1 \\
\hline Monoclorobenzeno (Sub) & $<0,001$ & $<0,001$ & $\mathrm{mg} / \mathrm{L}$ & 0,12 \\
\hline Sódio & $<3,0$ & 25 & $\mathrm{mg} / \mathrm{L}$ & 200 \\
\hline Sólidos dissolvidos totais & 45 & 238,15 & $\mathrm{mg} / \mathrm{L}$ & 1000 \\
\hline Sulfato & $<4,0$ & 31,5 & $\mathrm{mg} / \mathrm{L}$ & 250 \\
\hline Surfactantes & 0,06 & 0,86 & $\mathrm{mg} / \mathrm{L}$ & 0,5 \\
\hline Tolueno & $<0,001$ & $<0,001$ & $\mathrm{mg} / \mathrm{L}$ & 0,17 \\
\hline Turbidez & 0,7 & 13,1 & uT & 5,0 \\
\hline Zinco Total & $<0,07$ & $<0,07$ & $\mathrm{mg} / \mathrm{L}$ & 5,0 \\
\hline Xilenos & $<0,001$ & $<0,001$ & $\mathrm{mg} / \mathrm{L}$ & 0,3 \\
\hline
\end{tabular}

Fonte: Relatório de Ensaios LEA No 0118/14.

A água é um bem público indispensável para a vida e sua importância para a saúde pública é largamente reconhecida, entretanto, mais de um bilhão de pessoas em todo o mundo não têm acesso à água tratada, entre as quais 19 milhões residem no Brasil (RHEINGANS et al., 2006). 
Apesar da água ser um elemento essencial à vida, pode trazer riscos à saúde em face de sua má qualidade, servindo de veículo para vários agentes biológicos e químicos, por isso, o homem deve estar atento aos fatores que podem interferir negativamente na qualidade da água que consome e no seu destino final (SOARES et al., 2002).

Segundo o Ministério da Saúde, os grandes desafios da saúde ainda são, principalmente, as hepatites, a malária, a febre amarela, a cólera, a esquistossomose, o dengue, as leishmanioses, a hantavirose. Por essa lista, percebe-se a importância que ainda há nas doenças de veiculação hídrica ou que tenham como elo importante da cadeia o ambiente (ROCHA et al., 2006).

É comum o registro de contaminação por microrganismos patogênico nos mananciais cuja água é destinada ao consumo humano. A água um veículo de transmissão de agentes de doenças infecciosas e parasitárias, exigindo assim um tratamento adequado antes de ser colocada para o consumo (SANTOS et al., 2013).

Em relação aos dados epidemiológicos, observou-se que o município de Santo Amaro da Brotas apresentou um quadro de morbidade com internação por doenças infecciosas e parasitárias maior que o município de Malhada dos Bois quando se analisa os anos de 2010 à 2013 (Figura 2)

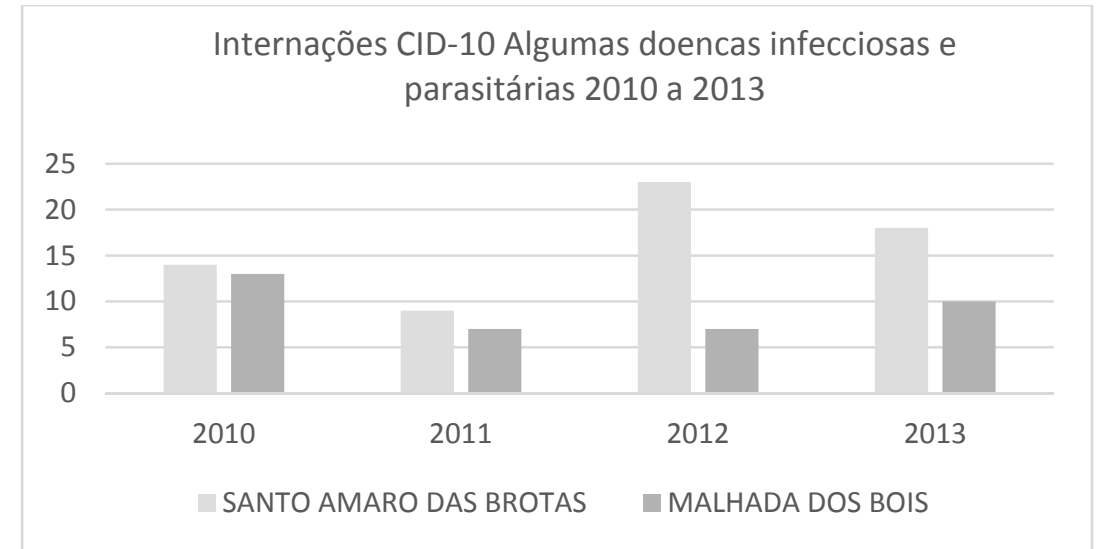

Figura 2: Internação por doenças infecciosas e parasitárias, em Santo Amaro das Brotas e Malhada dos Bois 2010 a 2013.

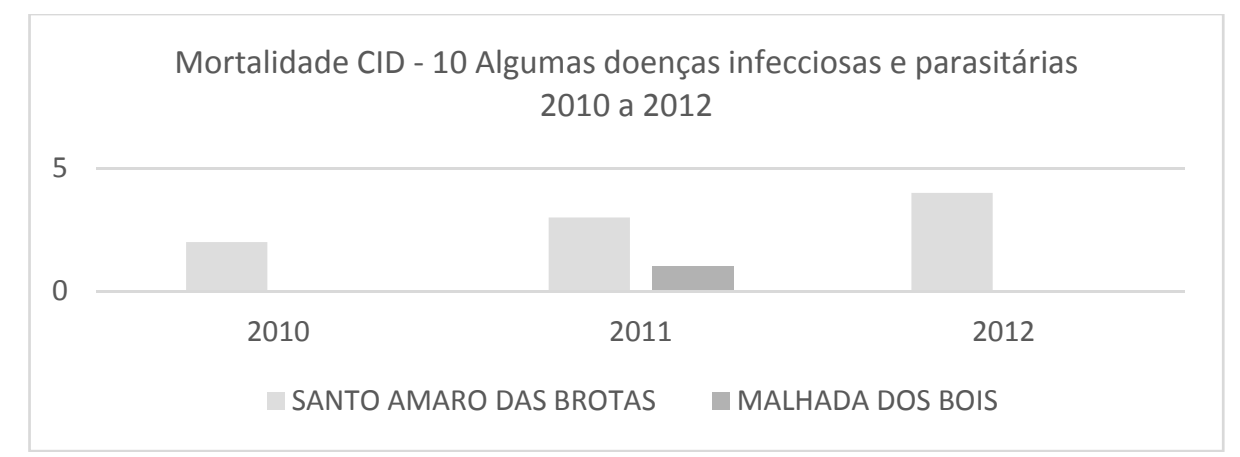

Figura 3: Mortalidade por doenças infecciosas e parasitárias em Santo Amaro das Brotas e Malhada dos Bois, 2010 a 2012.

Pode-se perceber o mesmo quando se observa a mortalidade por doenças infecciosas e parasitárias nos municípios de Santo Amaro das Brotas e Malhada dos Bois nos anos de 2010, 2011 e 2012. Houve somente um registro de óbito em Malhada dos Bois no ano de 2011 enquanto 
Santo Amaro apresentou 2 óbitos em 2010, 3 óbitos em 2011 e 4 óbitos em 2012 (Figura 3).

Esses dados corroboram com o estudo de Santos et al. (2013) em que foi possível verificar que os patógenos entéricos são os mais frequentemente encontrados entre os patógenos disseminados em fontes de água e que a presença desses microrganismos compõe uma das principais fontes de morbidade e mortalidade no mundo, principalmente, nos países em desenvolvimento.

\section{CONCLUSÃO}

O presente estudo identificou nos dados da coleta da amostra da água ETA do Município de Santa Amaro das Brotas para análise, a seguinte conclusão: para os parâmetros ensaiados na amostra, a cor aparente, o ferro total, os surfactantes e a turbidez estão em desacordo com a Portaria 2.914/2011 do Ministério da Saúde. É demonstrada por meio dos resultados das análise da água realizada na ETA de Malhada dos Bois que os parâmetros ensaiados nas amostras, satisfazem os limites do Ministério da Saúde.

Os resultados obtidos demonstram que a população de Santo Amaro das Brotas que é abastecida pelo manancial do Rio Tiloto da Bacia Hidrográfica do Rio Sergipe, estava provavelmente sem água tratada no momento da coleta. Pode-se concluir que possivelmente a ETA esteja precisando ser limpa para a retirada dos poluentes existentes para melhora da qualidade da água destinada ao consumo humano. É importante também manter os reservatórios domésticos em condições adequadas para que não venham alterar a qualidade da água para o abastecimento.

No que se refere a morbimortalidade, observa-se que no Município de Santo Amaro das Brotas, as doenças de vinculação hídrica relacionadas à qualidade da água foram presentes e crescentes no período estudado.

Uma medida que pode ser adotada e incentivada para a população com resultados bem sucedidos para a saúde pública, é a adoção de cloração da água para a desinfecção, protegendo desta forma, a população contra importantes doenças evitáveis que são as de veiculação hídrica (SCHOENY, 2010).

\section{REFERÊNCIAS}

BEZERRA, N.; SOUZA M. J.; PINHO, A. I.. Análise microbiológica da água de cisterna na localidade de Cipó dos Tomaz, município de Crato-CE. Caderno de Cultura e Ciência, v.4, n.1, 2010.

BOLAND J. J.; ANDERSON B. P.; BROOKS N. H.. Microbiol pathogens in coastal waters. In: Managing wastewater in coastal urban areas. USA: Committee on Wastewater Management for Coastal Urban Areas, Water Science and Technology Board, Commission on Engineering and Technical Systems. National Research Council, 1993.

BONOMI A. E., PATRICK D. L., BUSHNELL D. M., MARTIN M.. Validation of the United States' version of the World Health Organization Quality of Life (WHOQOL). Clin Epidemiol J, v.53, p.1-12, 2009.

BRASIL. Portaria n.518, de 25 de março de 2004. Estabelece os procedimentos relativos ao controle e vigilância da qualidade da água para consumo humano e seu padrão e potabilidade, e dá outras providencias, Brasília, 25 Mar 2004. 
BRASIL. Ministério da Saúde. Portaria n. 2914 de 25 de dezembro de 2011. Estabelece os parâmetros e responsabilidades relativos ao controle e vigilância da qualidade da água para consumo humano e seu padrão de potabilidade, e da outras providencias. Brasília, 25 Dez 2011.

BUSS, P. M.. Promoção da saúde e qualidade de vida. Ciência e Saúde Coletiva, v.5, n.1, p.163-177, 2000. DOI: http://dx.doi.org/10.1590/S1413-81232000000100014

CARLOS, A. A. G; KLIGERMAN, D. C.. a percepção das condições de saúde pública e ambiente de moradores de comunidades rurais e as questões do acesso à água potável: um estudo de caso. In: Congresso de Engenharia sanitária e Ambiental, 13. Anais. Campina Grande, 2005.

CHAPRA, S. C.. Surface water-quality modeling. Clin Epidemiol J., v.53, p.1-12, 2009.

FLECK, M. P. A.; LOUZADA, S.; XAVIER, M.; CHACHAMOVICH, E.; VIEIRA, G.; SANTOS, L.; PINZON, V.. Aplicação da versão em português do instrumento de avaliação de qualidade de vida da Organização Mundial da Saúde (WHOQOL-100). Rev. Saúde Públic. v.33, n.2, p.198-205, 1999.

HARBERMANN, M.; GOUVEIA, N.. Justiça ambiental: uma abordagem ecossocial em saúde. Revista de Saúde Pública, v.42, n.6, p.1105-1111, 2008.

IBGE. Pesquisa Nacional por Amostra de Domicílios Contínua. Aracaju, 2014.

ONU. Mudanças climáticas aumentam vulnerabilidade de deslocados. Conferência das Nações Unidas Sobre Desenvolvimento Sustentável, 2012.

PIMENTA, F. A. P.; SIMIL, F. F.; TÔRRES, H. O. G.; AMARAL, C. F. S. A.; REZENDE, C. F.; COLEHO, T. O.; REZENDE, N. A.. Avaliação da Qualidade de Vida de Aposentados com a Utilização do Questionário SF-36. Rev. Assoc. Med. Bras., v.54, n.1, p.55-60, 2008.

PRADO T.; MIAGOSTOVICH M. P.. Environmental virology and sanitation in Brazil: a arrative review. Caderno Saúde Pública, v.30, n.7, p.1367-1378, 2014.

RHEINGANS, R.; DREIBELBIS, R.; FREEMAN, M. C.. Beyond the Millennium Development Goals: public health challenges in water and sanitation. Glob Public Health, v.1, n.1, p.31-48, 2006.

ROCHA, C. M. B. M.; RODRIGUES, L. S.; COSTA, C. C.; OLIVEIRA, P. R.; SILVA, I. J.; JESUS, E. F. M.; ROLIM, R. G.. Avaliação da qualidade da água e percepção higiênico-sanitária na área rural de Lavras, Minas Gerais, Brasil, 1999-2000. Caderno de Saúde Publica, v.22, n.9, p.1967-1978, 2006.

ROSA T. E. C.; BENÍCIO, M. H. D.; ALVES, M. C. G. P.; LEBRÃO, M. L.. Structural and functional aspects of social support for the elderly in the city of São Paulo, Brazil. Caderno Saúde Pública, v.23, n.12, p.298292, 2007.

SANTOS, J. O.; SANTOS, R. M. S.; GOMES, M. A. D.; MIRANDA, R. C.; NÓBREGA, I. G. M.. A qualidade da água para o consumo humano: uma discussão necessária. Revista Brasileira de Gestão Ambiental RBGA, Pombal, v.7, n.2, p.19-26, 2013.

SANTOS, P. R.. Aspectos Epidemiológicos e Microbiológicos na Distribuição da Água Potável em Comunidades de João Pessoa - PB. Trabalho de Conclusão de Curso - Universidade Federal da Paraíba, João Pessoa, 2014.

SCHOENY, R.. Disinfection by-products: a question of balance. Environmentl Health Perpectives, 2010.

SOARES S. R.; BERNARDES R. S.; NETTO O. M.. Relações entre saneamento, saúde pública e meio ambiente: elementos para formulação de um modelo de planejamento em saneamento. Caderno de Saúde Pública, v.18, p.1713-1724, 2002.

UNESCO. United Nations, Educational, Scientific and Cultural Organization. Water in a changing world. 2009. 